Revista Eletrônica do Mestrado em Educação Ambienta1

Programa de Pós-Graduação em Educação Ambiental

\title{
Caminhar, olhar e perceber: Educação para conhecer e conservar o cerrado
}

\author{
Kele Conceição Alves Vilaça Amaral ${ }^{1}$ \\ Karla Cunha Pádua ${ }^{2}$
}

Resumo: Neste artigo, apresentamos e discutimos aspectos relacionados à natureza, à cultura e à educação na comunidade Capão do Berto, localizada no município mineiro de Jaboticatubas. Através da observação participante e de entrevistas narrativas, analisamos aspectos que demostram como os saberes tradicionais, que subsistem na comunidade amparados pela cultura oral e pela dupla experiência-sentido, contribuem para o uso equilibrado dos bens naturais e, consequentemente, para a conservação ambiental. Pelas trilhas de saberes e memórias, acompanhamos reflexões sobre a biodiversidade, a percepção ambiental e a cosmovisão que move a estreita relação que os moradores têm com o ambiente do cerrado através de um misto de tradição, crença e consciência ambiental.

Palavras-chave: Educação, Saberes tradicionais, Ambiente e Cultura.

\section{Caminar, mirar y percibir: Educación para conocer y conservar el cerrado}

Resumen: En este artículo, discutimos la relación ambiente, cultura y educación en la comunidad Capão do Berto, ubicada en el municipio "mineiro" de Jaboticatubas. Usamos los instrumentos de observación activa y entrevistas narradas para analizar aspectos que demuestran como los saberes tradicionales que permanecen en la comunidad, apoyados por la cultura oral y por la doble experiencia-sentido, contribuyen para el uso equilibrado de los bienes naturales y, consecuentemente, para la conservación ambiental. Por los caminos de saberes y memorias, acompañamos reflexiones sobre la percepción ambiental de la biodiversidad y la cosmovisión que mueve la estrecha relación de los habitantes con el ambiente del cerrado, mezclando tradición, creencias y conciencia ambiental.

Palabras-clave: Educación, Cerrado, Saberes Tradicionales y Ambiente.

\section{Walk, look, and realize: Education to know and conserve the cerrado}

\footnotetext{
${ }^{1}$ Mestra em Educação e Pedagoga pela Universidade do Estado de Minas Gerais (UEMG). Especialista em Educação Ambiental. Contato: kelevamaral@gmail.com

${ }^{2}$ Doutora em Educação pela Universidade Federal de Minas Gerais (UFMG). Professora na Faculdade de Educação (FaE) e no Programa de Pós-Graduação em Educação (PPGE) da Universidade do Estado de Minas Gerais (UEMG), Campus de Belo Horizonte (CBH). Conato: kcpadua@yahoo.com.br
} 


\begin{abstract}
In this article we discuss the relation between environment, culture and education in the community of Capão do Berto located in the municipality of Jaboticatubas, Minas Gerais. We use the instruments of participant observation and narrative interviews to analyze aspects that demonstrate how traditional knowledge, which subsists in the community supported by oral culture and double experience-meaning, contribute to the balanced use of natural assets and, consequently, to environmental conservation. Through the ways of knowledge and memories, we saw reflections about the environmental perception of biodiversity and the worldview that moves the close relationship of the residents with the environment of the cerrado and that mix tradition, belief and environmental awareness.
\end{abstract}

KEY-WORDS: Education, Cerrado, Traditional Knowledge and Environment

\title{
Introdução
}

Este texto apresenta resultados de uma pesquisa de mestrado desenvolvida entre os anos de 2016 e 2018, que teve como objetivo discutir aspectos relacionados à natureza, cultura e educação em uma das comunidades rurais que tradicionalmente ocupa as terras ao sul da Cadeia do Espinhaço, no município de Jaboticatubas, Minas Gerais. Investigar como a relação dos moradores com o ambiente do cerrado, os saberes tradicionais e o uso da dupla experiencia-sentido nos processos educativos se relacionam com a conservação ambiental foi a questão central que norteou todo o trabalho.

Esse questionamento se justifica em face aos graves problemas ambientais contemporâneos e a relevância do local escolhido para a investigação. A Comunidade Capão do Berto encontra-se em um local de grande importância ambiental pela vasta biodiversidade presente na região limítrofe entre os biomas Mata Atlântica e Cerrado, que dividem também duas importantes bacias hidrográficas brasileiras: a do São Francisco e a do Rio Doce.

Para realizarmos a investigação, percorrendo os caminhos daqueles que se estabeleceram na região vivendo com e do cerrado, priorizamos a observação participante e as entrevistas. Dessa forma, pudemos acompanhar a relação que os moradores estabeleciam com o ambiente, identificando os saberes tradicionais presentes no cotidiano e o processo educativo das novas gerações afim de "atender as pessoas e coisas, aprender com elas, e acompanhá-las em princípio e prática” (INGOLD, 2016, p. 407).

Recorremos a métodos que deixassem os interlocutores à vontade e optamos pelo uso das narrativas orais como "trocas mútuas provocadas pelo encontro etnográfico". À esteira de Hartmann (2012, p.185), a escolha pelas narrativas pessoais não teve como foco a integralidade biográfica dos sujeitos, mas a relação de suas histórias de vida com a história local e com a cultura da sociedade em que estão inseridos. Para isso, assumimos também a perspectiva de que a história oral não diz respeito só ao evento, mas também ao

Rev. Eletrônica Mestr. Educ. Ambient. Rio Grande, v. 36, n. 2, p. 105 -126, mai./ago. 2019. 
seu significado na vida dos sujeitos que o narram (PORTELLI, 2016) e de que a memória individual carrega em si elementos externos que a torna parte da memória coletiva do grupo social (HALBWACHS, 1990).

As entrevistas narrativas realizadas nos locais de convívio dos moradores, durante esse processo, tornaram-se, em muitos casos, "turnês guiadas" (MEDEIROS, 2010, p. 164) motivadas pela necessidade dos respondentes nos mostrarem aquilo a que se referiam. Aconteceram em situações cotidianas como o convite para conhecer um rio próximo ou a condução à casa de algum parente que nos ajudaria com informações para a pesquisa. Durante essas "entrevistas andantes" foi possível observar a relação dos moradores com o cerrado e suas maneiras próprias de olhar e perceber o ambiente em que vivem. Foi possível também, compreender como os saberes ecológicos tradicionais atuam no processo de educação dos mais jovens nas relações familiares, tornando-se "redescobertas orientadas" (INGOLD, 2010, p.19).

$\mathrm{Na}$ conversa com as crianças procuramos não impor tópicos, mas providenciar os recursos necessários para que elas expressassem as questões significativas a partir de suas próprias sensações e experiências. Através de trocas culturais que incluíram trilhas guiadas, desenhos e rodas de conversa, buscamos criar de um "auditório social para a fala" onde a hierarquia adulto/criança interferisse da menor maneira possível na expressão dos participantes (SILVA, 2012). Proporcionando, desse modo, um sentido "horizontal de compartilhamento" com liberdade para que atribuíssem de maneira independente suas "ações e significados" (ROCHA 2008, p.49). Atenção que se justifica pelo reconhecimento de que as crianças são também agentes sociais competentes para a ação, comunicação e para a troca cultural.

Conforme os dados foram sendo coletados e classificados, foram analisados segundo os critérios da hermenêutica dialética, que favorece uma compreensão das narrativas como resultantes de processos sociais e de conhecimento e "frutos de múltiplas determinações, mas com significado específico" de uma "realidade que se mostra e se esconde na comunicação" (MINAYO, 2000, p. 227). Nessa perspectiva, as análises aqui apresentadas, procuram entrelaçar dados empíricos, referenciais teóricos e consulta a documentos sobre a história local. Começaremos por uma contextualização do lugar pesquisado.

\section{Contextualizando a comunidade}

Rev. Eletrônica Mestr. Educ. Ambient. Rio Grande, v. 36, n. 2, p. 105 -126, mai./ago. 2019. 

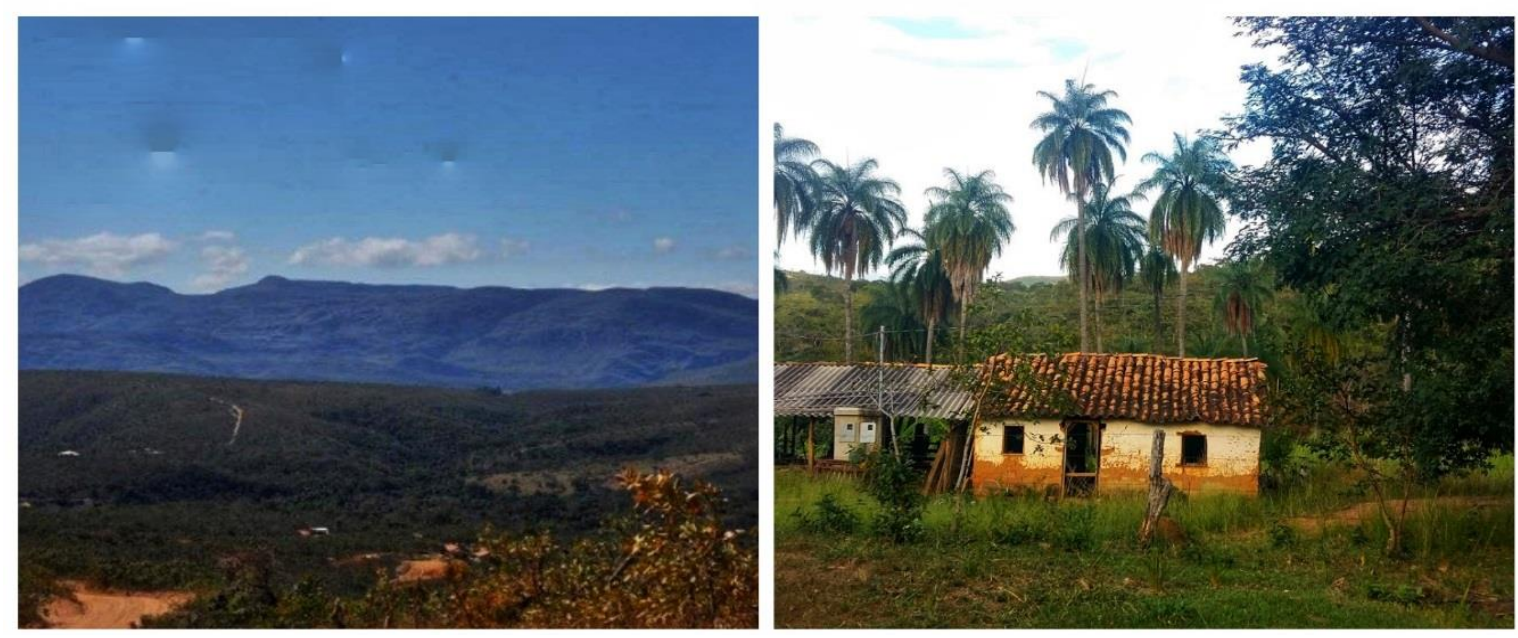

Figura 1: À esquerda, vista do alto da comunidade, à direita local da primeira propriedade adquirida pelo fundador João Apolinário. Fotos Amaral, 2017.

As terras tradicionalmente ocupadas (ALMEIDA, 2004) pela comunidade Capão do Berto, faziam parte da grande sesmaria concedida pelo governo português à Fazenda Santa Cruz do Cipó, fundada no séc. XVIII pelos irmãos Felicíssimo e João de Moraes. A fazenda era dedicada inicialmente ao cultivo da mamona, cujo óleo extraído era utilizado principalmente para iluminação pública. Em 1823, foi adquirida pelo Guarda-Mor José dos Santos Ferreira, que transformou o local em grande produtor de grãos. Após seu falecimento, a gestão de seus filhos expandiu os negócios transformando a Fazenda Cipó na maior produtora da região de itens como cana-de-açúcar, trigo e algodão. Segundo o historiador Leônidas Marques Afonso (1957, p.18-9), o empreendimento chegou a contar com "cem escravos de eito e numerosas escravas, animais e máquinas agrárias em abundância, embora rudimentares como eram todas daquele tempo".

Os descendentes dos escravos foram, portanto, os primeiros habitantes da comunidade. Os moradores mais antigos destacam a relevância da chegada do ex-escravo alforriado João Apolinário que, com o dinheiro recebido pelo trabalho como capataz, adquiriu as primeiras terras no local. Eles afirmam que por ser filho de uma escrava com um fazendeiro proeminente na região, Apolinário foi criado junto às senzalas, mas com alguns privilégios. Foi educado e tornou-se, ainda jovem, o responsável pelos escravos na fazenda, passando depois às atividades agropecuárias, concentradas principalmente no cultivo de algodão que lhe renderam lucro para a aquisição das terras onde formou a comunidade Capão do Berto.

O senhor Antônio, 80 anos, um dos moradores mais antigos da região, conta que João Apolinário era um homem inteligente e bom negociador, que ganhou o dinheiro que 
permitiu a ampliação do seu território principalmente através do cultivo de algodão. Ele diz:

Como começou tudo eu não sei, porque quando o seu João Apolinário mudou pra cá já morava um pessoal aqui e o lugar já tinha o nome de Berto [...] mas o lugar era só mato, ninguém plantava, não fazia lavoura, não tinha nada. Ele foi roçando, foi fazendo criação e foi comprando aos poucos e ficou sendo dono do lugar todo. Ele foi comprando tudo com o dinheiro do algodão. Plantava lavoura, ou então plantava milho, feijão, arroz, tudo. Mandiocal pra despesa, e plantava o algodoal no meio. Colhia os mantimentos e depois colhia o algodão na seca. O algodão dá é na seca e nesse tempo o algodão era muito vendável porque tinha fábrica lá em São Vicente. Ele vendia, juntava o dinheiro e ia comprando as partes do terreno com o dinheiro do algodão. (Sr. ANTÔNIO, 2017)

A Fábrica de tecidos São Vicente, mencionada pelo entrevistado, inaugurou suas instalações em Santa Luzia em 1880, com o intuito de aproveitar a farta colheita de algodão na região para a produção têxtil. Entretanto, problemas relacionados ao funcionamento das máquinas não permitiram que o empreendimento obtivesse o sucesso esperado nos primeiros anos, sendo vendido em 1891 para a Companhia de Fiação e Tecidos Cedro e Cachoeira, que já possuía a experiência de duas outras tecelagens, funcionando nas cidades do Cedro e na região de Curvelo (LIMA, 2009).

Próximo à comunidade Capão do Berto, funcionou também a Fábrica de Tecidos Cana do Reino, inaugurada em 1843, onde hoje se localiza o município de Santana do Riacho. A fábrica foi fundada pelos sócios ingleses Henry Pigot e Charles Cumberland, que trouxeram da terra natal o maquinário e o financiamento para o empreendimento. Todavia, um trágico acidente, ocorrido um ano após a inauguração, levou a óbito Henry Pigot, afogado nas águas do Rio Cipó, em um local que ficou conhecido como "poço dos ingleses" (LOPES FILHO e MAGALHÃES, 2014). Após esse período, a fábrica passou por diversos proprietários que não conseguiram contornar os problemas que envolviam, sobretudo, a escassez de mão de obra qualificada para a operação das máquinas, sendo finalmente fechada em 1874.

Apesar da história da formação da comunidade a partir dos escravos ser de conhecimento geral, poucos moradores se reconhecem como quilombolas. O assunto é contraditório no local e alguns preferem nem mesmo falar sobre isso. Percebemos que a não aceitação dessa ancestralidade escrava está ligada à negação de um passado considerado triste e vergonhoso. Um morador, que escolheu não ser identificado, comentou: "tem coisa do passado que é melhor deixar quieto lá, pra que lembrar coisa 
ruim?” Entretanto, o senhor Antônio, que já tentou mobilizar a comunidade no sentido de buscar a autoafirmação da identidade quilombola, acredita que o principal obstáculo seja o preconceito.

Existe preconceito, sempre existiu. As pessoas falam: ah! O preconceito tem que acabar! Tem que acabar, mas é difícil porque até as pessoas tem preconceito deles mesmos. Eles acham que ser negro é ser escravo e então não quer ser descendente de negro, sendo que é. Isso é por causa da doença do preconceito. (Sr. ANTÔNIO, 2017)

Já entre o grupo que faz questão de reconhecer suas origens, a reação é diferente. Alguns entendem a importância da autodeclaração e lamentam não ter o reconhecimento oficial que os vizinhos da comunidade do Açude já conquistaram. Esse reconhecimento é visto por esses moradores como uma espécie de honra.

Se por um lado essa relação com as origens quilombolas é contraditória, o mesmo não acontece com a herança rural. Ser da roça é uma colocação identitária assumida com orgulho. A agricultura familiar, cujas raízes culturais mantêm vivas as heranças do campesinato, mantém-se presente na relação entre propriedade, trabalho e família representando, apesar das dificuldades, a maior fonte de renda dos moradores da comunidade (WANDERLEY, 2003). Entre os diversos desafios que as famílias agricultoras enfrentam no cenário atual, destacam-se as alterações geradas pela desordenada expansão urbana sobre as áreas rurais no município.

Esse processo tem acarretado uma série de impactos ambientais que incluem: desmatamento, erosão, falta de água, poluição dos rios, perfuração irregular de poços artesianos, fossas construídas em locais inadequados, descarte de lixo no ambiente e poluição sonora. Tais impactos também atingem o modo de vida da comunidade que tenta se adaptar à chegada maciça dos novos moradores à região. A maior parte das construções que se multiplicam em forma de sítios, condomínios, empreendimentos de lazer e hospedagem nas proximidades da Serra do Cipó, atende ao interesse de grandes empresários que buscam tornar rentáveis as áreas verdes do município. Isso satisfaz uma demanda de citadinos que almejam por períodos de contato mais próximo com a natureza, mas ignoram os impactos de suas ações sobre o ambiente e vida das pessoas que dependem diretamente da interação ecológica e da gestão dos bens naturais para as atividades que lhes garantem a subsistência. 
Uma das formas encontradas pelos moradores do Capão do Berto para superar essas e outras dificuldades é, sem dúvida, a fé. As procissões e vigílias junto ao cruzeiro no alto da comunidade são marcas da intensa religiosidade local. A grande maioria dos moradores é católica, devota de São Sebastião, a quem foi dedicada a capela local em agradecimento pelo milagre atribuído ao santo que os teria livrado de uma epidemia que se alastrou sobre a região por volta da década de 1920. Entre as preces que constantemente se dirigem ao padroeiro, há um lugar especial para os pedidos em favor da natureza, que incluem a terra, as chuvas e todo o cerrado. Além da consciência da importância do equilíbrio ambiental para as práticas de agroextrativismo, os pedidos também refletem o vínculo que essa comunidade possui com o ambiente onde se processam e se multiplicam os saberes e as relações ambientais, como veremos a seguir.

\section{Saberes e relações ambientais no cerrado}

Caminhar é uma ação indispensável para compreender a relação que os moradores estabelecem com a natureza e o território. Durante as caminhadas, as longas conversas pelas trilhas de histórias e memórias revelaram, além dos conhecimentos tradicionais, a percepção, a ética e os significados que os moradores atribuem aos elementos naturais, especialmente os relacionados ao cerrado. Para estar aptos a acompanhar os que nos guiavam e compreender como eles percebiam e se relacionavam com o ambiente, nos esforçamos para manter os sentidos atentos como eles, pois "é possível ter olhos e não ver; ter ouvidos e não ouvir", conforme afirma Tuan (2012, p.30).

Parece que, diante da aguçada percepção dos que nos conduziam pelo cerrado, nada passava despercebido. Cada pequena fruta nativa no caminho era notada, assim como os rastros dos animais, o canto dos diferentes pássaros, os sons das cigarras e a presença dos insetos que anunciavam a esperada chuva. É fácil inferir que há entre eles uma compreensão sistêmica do ambiente, no qual cada elemento participa e desempenha funções determinadas em uma grande teia de relações que parece manter o sistema em equilíbrio, apesar das constantes agressões vinda do seu entorno.

Para esses moradores, o território é mais que uma área delimitada. É também um espaço identitário, de cultura, simbolismos, trajetórias e memórias que cooperam para torná-lo um lugar de pertencimento. Pertencimento que, nesse sentido não está vinculado à posse e à visão utilitarista da natureza, mas integra uma percepção cultural que enxerga 
que "todas as coisas vivas e os mundos social e natural estão intrinsecamente ligados" em um princípio de reciprocidade (TOLEDO e BARRERA-BASSOLS, 2015, p.72).

Tal mentalidade favorece uma relação voltada para o uso equilibrado dos bens naturais e, consequentemente, a conservação ambiental das áreas ocupadas por essas comunidades ditas tradicionais. ${ }^{3}$ Portanto, é mais que um simples ideal de preservação, mas uma noção de pertencimento que conduz as práticas locais que interligam cultura e natureza; intuição, percepção e vivência. Somente compreendendo essa relação é possível reconhecer como a permanência dessas populações em seus territórios contribui para a conservação ambiental.

A associação entre a permanência dessas comunidades nos territórios tradicionalmente ocupados e a conservação ambiental tem sido alvo de diferentes estudos nas últimas décadas. Motivados, na opinião de Arruda (1999), pela emergência da crise ambiental. O temor da iminente catástrofe ecológica anunciada lançou luz sobre o modo de vida sustentável das "comunidades de culturas rústicas e indígenas" que, através dos conhecimentos obtidos ao longo de gerações experimentando e observando minuciosamente os processos naturais, são capazes de viver de forma harmoniosa com o ambiente sem destruí-lo (ARRUDA, 1999, p.81-2).

Os modos de vida de algumas dessas comunidades tornaram-se, portanto, lembretes vivos de que é possível um relacionamento não utilitário com a natureza, em que a ação humana possa, inclusive, estimular a biodiversidade. Entre os estudos que abordam essa relação, Marques (2001) apresenta como os conhecimentos sobre taxonomia, hábitos dos peixes e as técnicas de manipulação dos pescadores artesanais corroboram para a manutenção da vida nos rios alagoanos. Também Diegues (2001), discutindo os contrapontos entre preservacionismo e conservadorismo, mostra como a presença das populações tradicionais nas áreas de reservas favorece a diversidade biológica. Todavia, o reconhecimento do papel desempenhado por essas comunidades não é suficiente para que as políticas públicas as protejam da invasão de seus territórios e da consequente destruição socioambiental.

É preciso reconhecer também que nem todas as comunidades ditas tradicionais realizam suas atividades de forma sustentável. Carneiro da Cunha e Almeida (2009) elaboram essa questão dissertando que o ambientalismo pode ser percebido nessas

\footnotetext{
${ }^{3} \mathrm{O}$ tradicional que assumimos nessa expressão reconhece que tais comunidades são constituídas por uma cultura que é viva e que se molda tanto a partir da herança dos antepassados, quanto pelas modificações que lhes atribuem os agentes sociais no cotidiano.
}

Rev. Eletrônica Mestr. Educ. Ambient. Rio Grande, v. 36, n. 2, p. 105 -126, mai./ago. 2019. 
comunidades de três formas: elas podem ser portadoras de uma ideologia conservacionista, mas não executarem ações efetivas; podem possuir tanto práticas sustentáveis quanto uma cosmologia que se relacione com tais práticas ou podem ter hábitos culturais que, dentro do contexto em que as pessoas vivem, sejam sustentáveis, mesmo sem o móbil de uma ideologia que expressamente as incline à conservação ambiental.

O que não se pode negar, é que mesmo os grupos que buscam modos de vida sustentáveis são afetados pelas consequências dos problemas ambientais contemporâneos. Esses refletem a crise de uma racionalidade antropocêntrica, cujas concepções metafísicas, filosóficas, éticas, científicas e tecnológicas conduziram a humanidade a uma relação parasitária com a natureza, em que não se diferencia o "uso do abuso" (LEFF, 2003; SERRES, 1990). No contexto do cerrado, a complexa matriz ambiental onde está inserida a comunidade Capão do Berto, a intervenção humana baseada nessa visão mercantil da natureza tem produzido um acelerado processo de degradação e incalculáveis danos socioambientais.

As consequências dessa "capitalização da ordem da vida" são sentidas pela comunidade, que imersa em uma relação de cultura e subsistência, busca formas de uso sustentável do cerrado, consciente de que dele vêm os frutos para alimento, as plantas para fins medicinais e rituais religiosos, a madeira para as construções. Práticas extrativistas onde a necessidade de respeitar os limites naturais é lembrada pelos moradores e ensinada às novas gerações, tornando-as desde crianças conhecedoras do rico ambiente em que vivem (SERRES, 1990).

Para as crianças da comunidade, o cerrado não é só mais um dos biomas aprendidos na escola, é o quintal de casa. É lugar onde se (con)vive e de onde vem parte do sustento da família. Por meio dessa relação, aqueles que vivem na região percebem, desde muito jovens, que cuidar do cerrado, das árvores nativas, dos animais e das águas do rio Cipó significa cuidar do que representa parte da identidade coletiva.

Quando chegamos à região, achamos curioso observar a frequência com que os moradores referem-se ao cerrado. Os caminhos que percorremos entre uma casa e outra não eram chamados de trilha ou mato como supúnhamos. A frase "vamos andando pelo cerrado" foi repetida diversas vezes, até mesmo pelas crianças. O que pode parecer uma simples nomenclatura revela um aspecto importante para a conservação ambiental: o conhecimento. Todas as crianças com quem conversamos, a menor delas com apenas 4 anos, foram capazes de identificar elementos típicos do cerrado, como animais, árvores, 
frutos nativos e ervas usadas para fins medicinais, além de perceber com facilidade diversas interações ecológicas no ambiente.

É o que nos mostrou Joana, garota de 10 anos, ao nos apresentar as cores e os sabores de diversas frutas nativas durante os caminhos que percorremos na comunidade Capão do Berto. "Você já viu pé de jamborô??"; "experimenta essa fruta, é uma delícia, chama sangue de Cristo"; "esse aqui é o pé do coco de macaúba"; "aquela é a mangaba". m um dos percursos entre sua casa e a de seu avô, naquele mês de outubro de 2017, ela os instruiu dizendo: "Tem muita fruta boa na beira da estrada, é só você olhar bem”.
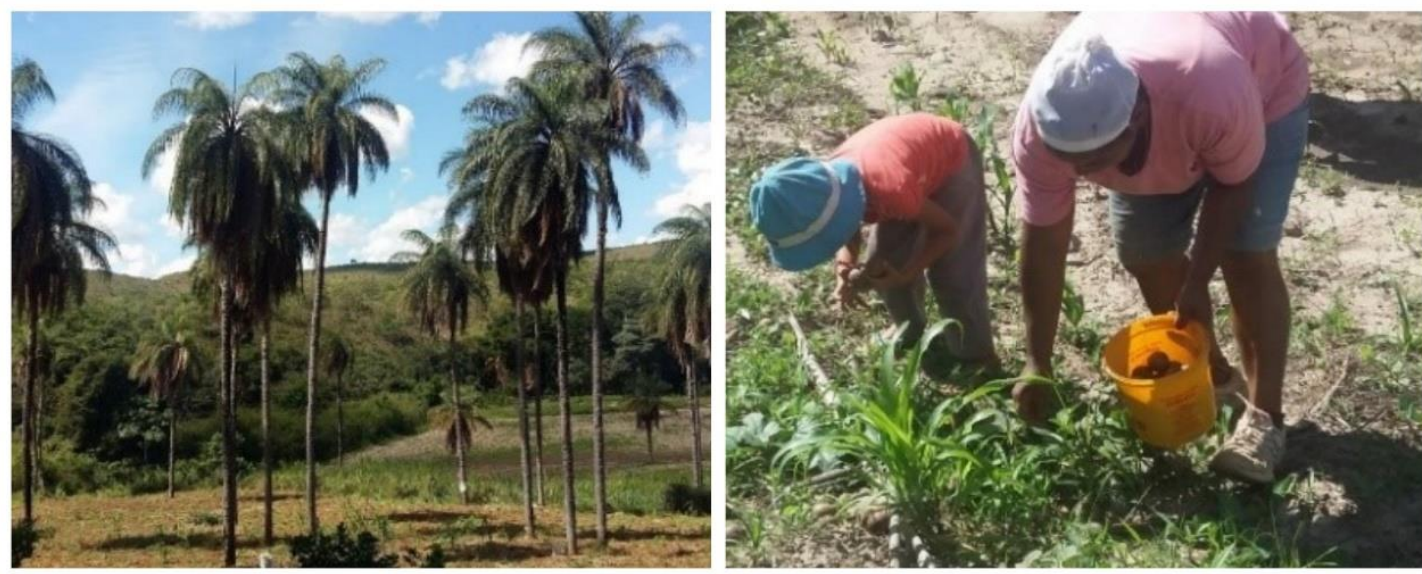

Figura 2: À esquerda palmeiras de Macaúba na comunidade e à direita mãe e filha recolhendo os frutos para o beneficiamento. Fotos Amaral, 2017.

As crianças demonstraram também ciência de que a manutenção dessa biodiversidade depende diretamente da conservação ambiental. A natureza proporciona as condições necessárias que cada espécie precisa para sobreviver e se reproduzir e, embora existam processos naturais que possam provocar o desaparecimento de uma espécie, as ações antrópicas respondem atualmente pelo avanço de um novo ciclo de extinção sem precedentes na história da terra. Neste período em que vivemos, chamado por alguns autores de Antropoceno ${ }^{5}$, o impacto das ações humanas - decorrente do modo de vida industrial, do uso de combustíveis poluentes, excesso de consumo e descarte - assumiu a "dimensão de uma força física dominante no planeta", mais ameaçadora que qualquer desastre natural. (VIVEIROS DE CASTRO, 2015, p.24)

Concordando com essa perspectiva, mencionamos a gravidade de alguns fatos, tal como a perda de habitat como sendo a principal causa de extinção de espécies em qualquer

\footnotetext{
${ }^{4}$ Utilizamos os nomes das espécies da fauna e flora apenas como são conhecidos localmente.

${ }^{5} \mathrm{O}$ Antropoceno é um conceito, proposto inicialmente por Paul Crutzen, que trata das mudanças geológicas ocasionadas pelas intervenções humanas sobre o ambiente a partir da revolução industrial, que têm gerado como consequência diversas alterações físicas e climáticas no planeta como a ampliação do fenômeno do aquecimento global por exemplo. Para mais informações sobre o tema:

https://doi.org/10.11606/issn.2316-9036.v0i103p13-24 Acesso em:29 de jan. 2018.
}

Rev. Eletrônica Mestr. Educ. Ambient. Rio Grande, v. 36, n. 2, p. 105 -126, mai./ago. 2019. 
bioma, segundo dados do Ministério do Meio Ambiente (MMA) ${ }^{6}$. No caso do cerrado, fauna e flora sofrem com as pressões causadas pela ocupação das áreas naturais, a exploração insustentável do ambiente e o desmatamento. Ações antrópicas já causaram a extinção de muitas espécies e ameaçam a vida de outras de forma crescente.

Conversando com os moradores de Capão do Berto, ouvimos vários relatos que demonstram como eles percebem as agressões ao cerrado. Dona Vivina, de 77 anos, comenta que quando se mudou para a região, há mais de 60 anos, passou muitas noites em claro temendo os lobos-guará, que em grande número rodeavam a casa e uivavam até o amanhecer. Atualmente, a espécie ameaçada de extinção já não é vista nos arredores. O tatu-galinha é outra espécie que, segundo os moradores, vivia em grande número na região e hoje raramente é encontrada, assim como as jaguatiricas e os tamanduás.

A presença de alguns animais da fauna silvestre, que ainda são avistados nas comunidades, foi relatada por alguns moradores. Foram lembrados também o gambá, veado, jacu, saracura, inhambu, tucano, anu e souin. Algumas relações ecológicas observadas por eles na presença de alguns desses animais também foram descritas, como relata Marcos, de 15 anos: "Escuta esse canto, é o canto das siriemas, elas andam assim em grupo pra caçar as cobras, mas comem pintinho e bicho pequeno também”. Dorizania, que também participa da nossa conversa, complementa:

E o urubu não come só carniça, ele também rói o coco da macaúba, ele e o caxinguelo. O papa-mel também tem muito aqui, ele come cana, fruta e tudo quanto é coisa doce, e as capivaras que comem coisas de raiz e fuçam por todo lugar que anda e são um problema pra gente na plantação de mandioquinha. (DORIZÂNIA, 2017)

O cerrado brasileiro possui a mais rica savana do mundo em diversidade biológica, com quase doze mil espécies de plantas nativas, mais de mil espécies de mamíferos e aves, além de um elevado número de peixes, répteis e anfíbios, muitos, ameaçados de extinção, segundo do MMA. Além da riqueza da fauna e flora, a existência de diversas espécies endêmicas faz desse que é o segundo maior bioma da América Latina, um dos hotspots ${ }^{7}$ mundiais de biodiversidade.

\footnotetext{
${ }^{6}$ Fonte:<http://www.mma.gov.br/biomas/cerrado> acesso em 14 out.2017

${ }^{7} \mathrm{O}$ termo hotspots foi criado por Norman Myers em 1988 e adotado pela Conservação Internacional para designar as regiões biologicamente mais ricas, e ameaçadas, do planeta. Designa áreas onde há um número elevado de espécies de plantas vasculares endêmicas (superior a 1500 espécies) e pelo menos 30\% de sua vegetação original preservada.
}

Rev. Eletrônica Mestr. Educ. Ambient. Rio Grande, v. 36, n. 2, p. 105 -126, mai./ago. 2019. 
Somados a essa biodiversidade, fatores como a localização geográfica elevada, a passagem de trechos importantes das principais bacias hidrográficas sul-americanas, as características da vegetação nativa e a permeabilidade do solo conferem ao cerrado uma incalculável relevância na disponibilidade hídrica de todo o país. A reserva de água tem sido gravemente afetada devido ao avanço do desmatamento para a monocultura intensiva e pecuária. Esses processos alteram o ciclo natural de recarga dos aquíferos e a capacidade de absorção dos solos, secando nascentes e rios que dependem das raízes profundas das árvores para o transporte das águas das chuvas aos lençóis freáticos.

É preciso reconhecer também a participação dos garimpos e mineradoras no processo de destruição dos habitats no cerrado. Todavia, esse importante bioma possui ainda outros algozes. No contexto da região serrana de Jaboticatubas, onde se localiza a comunidade Capão do Berto, como já foi dito, a expansão imobiliária acelerada pelo crescente número de turistas tem contribuído de forma incisiva com o desmatamento de áreas nativas, o desvio e a poluição de cursos d'água, o parcelamento irregular do solo entre outros problemas resultantes da incorporação da natureza ao capital, ( LEFF, 2003) o que compromete cada vez mais a vida de todos aqueles que mantém uma relação com o cerrado que envolve, além da subsistência, cultura e educação.

\section{A educação da atenção e as redescobertas orientadas}

Desde os primeiros dias de convivência com os moradores do Capão do Berto, ficou claro para nós que os conhecimentos ecológicos tradicionais se perpetuavam na comunidade. Restava saber de que modo o processo ocorria, o que se tornou claro na continuidade da observação, à luz da leitura de Ingold (2010). Como esse autor, buscávamos uma resposta local às questões sobre como ocorre a transmissão dos saberes entre as gerações e sobre o papel da experiência vivida nesse processo.

Desconstruindo a distinção entre mecanismos cognitivos inatos e conteúdo cultural adquirido, Ingold (2010, p. 7) afirma que o conhecimento "consiste em primeiro lugar, em habilidades e que todo ser humano é um centro de percepções e agência em um campo de prática". Tais habilidades se processam na vida diária de forma sistemática e dinâmica. E através do que Ingold chama de "educação da atenção" (2010, p. 7), tais formas de conhecimentos são edificadas em processos que relacionam percepção ambiental, conhecimento empírico e vivência dialogal com os mais velhos, como o autor explica: 
Não se trata de conhecimento que me foi comunicado; trata-se de conhecimento que eu mesmo construí seguindo os mesmos caminhos dos meus predecessores e orientado por eles. Em suma, o aumento do conhecimento na história de vida de uma pessoa não é um resultado de transmissão de informação, mas sim de redescoberta orientada. (INGOLD, 2010, p.19)

Sujeitos ativos nesse processo, as crianças da comunidade do Berto utilizam as habilidades adquiridas para processar essas "redescobertas orientadas". Tomemos como exemplo novamente o relato de Joana sobre como aprender a identificar os frutos do Cerrado.

\begin{abstract}
Quando eu to andando com minha mãe pelo Cerrado, às vezes indo pra casa de alguma pessoa, aí eu vejo uma fruta diferente eu pergunto pra minha mãe: mãe o que que é isso? Aí ela fala o nome pra mim e se pode provar, aí eu provo. Aí eu fico com o nome da fruta na cabeça. Se seu gostei eu não esqueço mais o nome da fruta. Se eu não gostei nem sempre eu lembro, mas assim eu vou aprendendo. (JOANA, 2017)
\end{abstract}

Notemos que, se no cenário que a criança narra, ela se detivesse a perguntar à mãe o nome da fruta, ela não estaria adquirindo um conhecimento, apenas uma informação. Porém, como ela vai além e tem a experiência de observar o ambiente, provar a fruta, perguntar seu nome e decidir memorizar ou não, a junção das novas informações (auditivas, visuais e sensoriais) às suas habilidades se transforma em conhecimento. É possível, portanto, concluir que não é exatamente o conhecimento que os mais velhos transmitem às novas gerações, mas sim as vivências, por meio das quais os jovens construirão o próprio conhecimento.

Percebemos que o compartilhar de tais experiências na vida diária da comunidade é realizado por mestres capazes de oferecer mais que bons discursos, pessoas que apresentam junto ao que falam um saber/fazer repleto de exemplos de vida. Em suma, ensinam o que fazer mostrando como fazem. Ingold (2010) aborda essa questão ao falar sobre a importância da noção de "mostrar" no processo de aprendizado por redescobrimento dirigido. Segundo o autor, "Mostrar alguma coisa a alguém é fazer esta coisa se tornar presente para esta pessoa, de modo que ela possa apreendê-la diretamente, seja olhando, ouvindo ou sentindo" (p. 21).

Com efeito, as conversas mais reveladoras que tivemos com os moradores acerca do modo como os conhecimentos são perpetuados não aconteceram nas sempre fartas mesas de café, mas durante as "andanças". Grande parte das entrevistas iniciadas nas cozinhas terminava em uma volta pelo quintal através do convite: vamos ali que eu mostro 
e vou falando. Essa forma peculiar de relatar os fatos, com a necessidade empírica de mostrar a que se referem, é bastante reveladora sobre como funciona o processo de ensino/aprendizagem através do qual os valores e a sabedoria locais são transmitidos.

Nos momentos em que participávamos dessas caminhadas, estivemos sujeitos ao mesmo processo de ensino aos quais os moradores estão tão familiarizados e, por meio dele, aprendemos várias coisas. Através da relação social estabelecida no campo, absorvemos muito além de informações que serviriam para ser descritas nas linhas deste texto, vivenciamos situações que contribuíram também para nosso crescimento pessoal e, em posse delas, escolhemos narrar os encontros e as ações dos sujeitos com quem caminhamos mergulhados nesse intercâmbio de experiências. Conforme afirma Ingold, “praticar observação participante também é ser educado” (2016, p. 407).

Para exemplificar mais uma vez esse processo de ensino pelo mostrar ao qual nos referimos, vejamos a fala de Gabriel, de nove anos: "Sei muita coisa do Cerrado, aprendi tudo com o vovô, tem hora que nós vai buscar as vacas aí a gente vai pelo cerrado afora conversando e ele me mostra as coisas. E eu também sou muito curioso e pergunto tudo [...]". Ele declara ter aprendido sobre a importância da conservação do Cerrado com o avô Antônio que explica e mostra as coisas enquanto eles caminham.

Fomos, então, visitar seu avô para saber mais sobre como ocorre esse processo de ensino. Após poucos minutos de conversa, ele nos convidou para caminhar em suas terras e exibiu centenas de árvores plantadas por ele, explicando, enquanto andávamos, sobre a importância da conservação da mata para a preservação do solo e das águas. Através do mesmo processo que utiliza para ensinar os netos, o senhor Antônio nos mostrou que mesmo nos locais destinados ao pasto, sempre se preocupou em semear espécies nativas do Cerrado, para que estas pudessem reparar de alguma forma os danos trazidos pelo capimbraquiária, utilizado para alimentação do pequeno rebanho bovino. Ele diz:

Mesmo aqui onde a criação anda, eu sempre jogo umas sementinhas pra não ficar pelado porque eu não gosto não. Esse aqui é pau terra tem de três qualidades dele aqui. Tem pau terrinha que é inferior, tem o pau terrão que é uma madeira especial pra cerca e [...] esse pau terrinha, pra poste ele não vale nada, agora, ele serve pra terra, pra natureza, [...], você deve ter estudado, mas nem sempre estuda tudo, isso aqui, o cerrado é a mãe d'água, se você monta num cavalo e chupa o sangue dele todo, o cavalo morre de fraqueza, porque chupou o sangue todo. A braquiara na terra é assim, chupa a água, mas não devolve. Agora, isso aqui não! Pega na folha dessa árvore pra você ver, quebra ela, e olha que folha gorda, você ta vendo isso? É assim: a raiz dela tá conservando a água lá, por isso a rama tá desse jeito aqui. A hora que ela cair na terra ela vai devolver pra

Rev. Eletrônica Mestr. Educ. Ambient. Rio Grande, v. 36, n. 2, p. 105 -126, mai./ago. 2019. 
terra tudo o que tirou daí, então olha a importância que tem! (Sr. ANTÔNIO, 2017)

Em meio a esse modelo de ensino/aprendizagem ativo, que constrói sentidos para a vida, há "um processo que envolve transformações no sujeito que aprende e incide sobre sua identidade e posturas diante do mundo" (CARVALHO, 2001, p.49). Dessa forma, os conhecimentos ecológicos tradicionais se perpetuam e permitem que os mais jovens reconheçam a importância da conservação das espécies e da conservação ambiental para a manutenção do modo de vida agroextrativista.

Mesmo com a incursão de muitos elementos da vida moderna, as práticas tradicionais milenares de convivência com esse bioma, mantêm-se pouco alteradas na comunidade, o que pode ser observado se compararmos como viviam os primeiros habitantes do cerrado, segundo o relato de Ribeiro (2009):

A grande variedade de flora e de fauna, bem como de paisagens, permitiu a presença de grupos humanos no Cerrado há mais de 10 mil anos. Restos de caroços de pequi e de coquinhos de licuri e ossos de veado e tatu, encontrados em pesquisas arqueológicas realizadas em grutas de Minas Gerais e Goiás, revelam como são antigos os usos de seus recursos naturais na alimentação. Coletando frutos e palmitos, caçando e pescando, os primeiros moradores aprenderam a retirar do Cerrado o que era necessário para sua existência. Por volta de dois mil anos antes de Cristo, esses Povos do Cerrado já viviam também de suas roças, plantavam milho e amendoim, fabricavam vasilhas de barro, produziam tecidos, esteiras e cordas de embira. Dessa forma, esses povos desenvolveram um modo de vida diferente daquele dos moradores dos mangues e matas do litoral, da Floresta Amazônica, dos campos frios do Sul, ou das altitudes dos Andes (p.29).

Para essas comunidades que aprenderam a viver no e do Cerrado, ele é fonte, não só de alimento, mas também de cura. "A melhor farmácia do mundo é essa aqui", diz o senhor Antônio. A primeira opção em caso de um mal-estar é sempre recorrer aos chás e preparos naturais. A busca por hospitais e medicamentos alopáticos só é feita em casos extremos, não apenas pela dificuldade de acesso a tais serviços, mas pela confiança na eficácia dos tratamentos naturais. Os conhecimentos que envolvem o modo de utilização de cada folha, raiz ou erva são repassados de geração em geração em um processo contínuo de transmissão de saberes através da relação com o ambiente. E envolvem, além da identificação correta de cada espécie, o manuseio preciso - da colheita ao preparo - e a administração correta das doses de acordo com o tratamento a ser realizado.

A título de exemplo dos conhecimentos tradicionais associados ao uso de plantas medicinais, destacamos alguns dos preparos indicados pelos moradores. A casca de romã, 
além de ser benéfica à garganta, é útil para combater os vermes e regular os "ciclos femininos". Dom Bernardo é um forte depurativo, usado no tratamento de furúnculos. O fruto do gravatá, parecido com o abacaxi, é apontado nas comunidades como um "santo remédio" para quem tem bronquite e asma. Santa Maria, uma erva muito amarga, é utilizada como purgante no tratamento de vermes e aplicada também como pesticida natural, como explica Dorizânia: "se você tiver com uma galinha de pintinho no galinheiro cheia de piolho no ninho, é só pegar e esfregar santa maria no ninho, sai um insumo verdinho e não sobra um piolho".

Quanto ao extrativismo dos frutos do cerrado, consumidos in natura ou beneficiados para uso próprio ou comercialização, a lista é extensa e inclui pequi, jatobá, graviola, jamborô, jenipapo, mangaba, cagaita, cajuzinho-do-cerrado, lobeira, entre diversos outros, entre os quais destaco a macaúba pela importância histórica, cultural e econômica na região. A origem da utilização da macaúba remete a períodos pré-históricos, há relatos de extrativismo que datam de cerca de 9000 anos A.C. Já os processos de beneficiamento do fruto foram se desenvolvendo ao longo da história. Da macaúba, tudo é aproveitado. O óleo obtido a partir do cozimento e torra das castanhas é apreciado no uso culinário por ser rico em vitaminas E e C, ômega 3, 6, 9, além de betacaroteno. A gordura resultante da polpa é utilizada na indústria de biocombustíveis e para produção de sabão. A torta da polpa é matéria prima para a ração animal e do endocarpo do fruto é feito carvão vegetal (CARVALHO et al., 2011).

A importância gastronômica e cultural do óleo de macaúba, produzido pelas comunidades de Jaboticatubas, foi nacionalmente reconhecida em 2017 a partir da inclusão do alimento na Arca do Gosto $^{8}$. Uma iniciativa do movimento SlowFood, que atua na região em parceria com a Associação $\mathrm{Amanu}^{9}$, em um programa que visa a preservação do patrimônio gastronômico e socioambiental. Com esse objetivo, o SlowFood iniciou na comunidade Capão do Berto o projeto "Fortaleza do coco macaúba", resgatando as memórias culturais e afetivas que envolvem a produção desse alimento.

Essas ações integram o projeto Uso sustentável da macaúba, da Associação Amanu, que tem buscado em toda a região de Jaboticatubas mobilizar, apoiar e capacitar as

\footnotetext{
8 Fonte: <http://www.slowfoodbrasil.com/arca-do-gosto/produtos-do-brasil/1331-oleo-de-macauba $>$ acesso em 04 mar 2018.

9 A Amanu é uma associação civil, sem fins lucrativos, formada por agricultores familiares, artesãos, produtores artesanais, moradores do campo, comunidades tradicionais, técnicos e voluntários que atua no sentido de mobilizar e apoiar ações populares comprometidas com uma sociedade mais justa e ecológica em Jaboticatubas.
}

Rev. Eletrônica Mestr. Educ. Ambient. Rio Grande, v. 36, n. 2, p. 105 -126, mai./ago. 2019. 
comunidades envolvidas no extrativismo do coco, para que as estratégias sustentáveis de beneficiamento promovam melhoria de renda para as famílias e conservação ambiental. É também parte desse projeto a construção da Casa Comunitária do Coco Macaúba, iniciativa que visa estimular o aumento da produção e a renda do tradicional beneficiamento da macaúba, realizado há gerações pelas comunidades de Jaboticatubas.

Com o maquinário moderno já adquirido pela associação, as famílias poderão agilizar e aperfeiçoar os processos, produzindo e administrando coletivamente a fabricação dos diversos produtos obtidos a partir da macaúba, como óleo de coco extravirgem, ração orgânica, sabão, sabonete, entre outros, sem abrir mão da tradição. Nessa perspectiva, considera-se que o beneficiamento do fruto não é o modus operandi da tradição local e nem um patrimônio de "pedra e cal” (GONÇALVES, 2009), mas é um costume inserido em uma cultura viva, passível de adaptações a novas estruturas por seus atores sociais.

Vale lembrar que iniciativas como essa, além de contribuírem para a salvaguarda do patrimônio biocultural e para a conservação do cerrado, valorizam os trabalhadores rurais que, com o apoio necessário, podem manter as raízes culturais do extrativismo, enquanto controlam coletivamente o processo produtivo - que se torna menos pesado com a ajuda das máquinas. E têm, por fim, os produtos vendidos sem atravessadores, pelo preço justo, através da economia solidária.

Os processos que envolvem o extrativismo e o sentimento dos moradores em relação ao cerrado refletem uma relação que extrapola uma simples consciência de conservação. O vínculo com o território, as experiências, a memória e a fé conduzem a vida comunitária através de uma ecologia que não se encontra nos livros, mas está marcada na mente e nos corações daqueles que (com)vivem com o cerrado.

Parte dessa percepção, profundamente ligada ao ambiente, forma o elo afetivo que une os indivíduos ao lugar. É o que Tuan em 1974 conceituou como Topofilia. Segundo o autor, a limitação ou a ampliação dessa capacidade envolve, além de aspectos físicos individuais, fortes elementos culturais que possibilitam ao nativo observar o ambiente em que vive de forma complexa, "derivada de sua imersão na totalidade" (TUAN, 2012, p.28, $30,96)$

É possível observar, através das memórias narradas, a percepção e os sentimentos envolvidos em relação ao lugar. Com esse intuito, ouvi muitas histórias - alegres e tristes como as do tempo dos plantios de grandes roças, em que as famílias unidas em mutirão trocavam em "camaradagem" dias de trabalho, plantando arroz, feijão, milho e amendoim. Por vezes, essa prática culminava em grande fartura, em outras, safras completamente 
perdidas porque a aguardada chuva não veio - mesmo depois de muito trabalho no cultivo do solo. Felizes ou não, as histórias têm em comum um enredo que narra a relação com o ambiente e as construções identitárias, afetivas e sociais feitas através desse elo.

Nessas trocas ambientais, a percepção e a relação com o lugar se formam munidas de experiências e significados. A terra - para os que vivem do agroextrativismo- é embebida de sentidos e significados, atribuídos pela cultura que envolve as diversas dimensões da vida. O conceito de lugar é compreendido, portanto, como algo que além de envolver o ambiente físico, abarca as memórias individuais, coletivas e os sentimentos e constitui um espaço munido de valor, história e afetividade.

Ferreira (2000) apresenta um breve histórico sobre as discussões em torno do conceito de lugar para geografia ao longo das últimas décadas, desde os primeiros levantamentos às recentes teorizações sob a ótica das mudanças contemporâneas postuladas por nomes como Oakes e Merrifield. Considerei as teorias mais recentes, contudo, minha leitura sobre a relação que as comunidades participantes exercem com o lugar não dialoga com nenhuma delas, mas encontra-se perfeitamente abrigada na Geografia Humanista e em seus preceitos de identificação do lugar a partir da vivência profunda com o território tradicionalmente ocupado.

Os moradores da comunidade Capão do Berto enxergam o lugar sob um olhar fenomenológico, percebendo-o como um "núcleo de valor" e atribuem a ele "uma profunda e imediata experiência do mundo que é ocupado com significados e, como tal, é a própria base da existência humana" (RELPH, 1980, p. 5 apud FERREIRA, 2000, p. 67). Nesse contexto, os antecedentes do passado histórico e os que contribuíram para a formação do lugar são relembrados e essa memória favorece o fortalecimento da identidade coletiva e da formação educativa.

\section{Considerações finais}

Observar a vida cotidiana das pessoas na comunidade do Capão do Berto, nos permitiu compreender como saberes, memória e educação são aspectos indissociáveis. Durante este estudo, procuramos compreender as articulações entre natureza e cultura, observando como os saberes tradicionais subsistem e se perpetuam na comunidade. Para isso, acompanhamos o dia a dia dos moradores, ouvimos suas histórias, observamos o manejo do ecossistema e buscamos compreender as tradições que regem as ações desses atores sobre o ambiente.

Rev. Eletrônica Mestr. Educ. Ambient. Rio Grande, v. 36, n. 2, p. 105 -126, mai./ago. 2019. 
Pelas trilhas de saberes e memórias, foi possível observar a estreita relação que os moradores têm com o ambiente do Cerrado, do qual cuidam não somente pela consciência conservacionista, mas também como resposta ao que o ambiente provê para muitas famílias que vivem do agroextrativismo. Nesse sentido, a cosmovisão que os move envolve um misto de tradição, crença e consciência ambiental.

Foi possível observar, também, que o pertencimento ao lugar e o vínculo com o território marcam as relações, inclusive das crianças, com o ambiente em que vivem. Estas revelaram, em meio às "andanças pelo Cerrado", o domínio de conhecimentos ecológicos tradicionais, construídos a partir do arcabouço de cultura e experiência transmitidas pelos mais velhos. Esses mestres do saber/fazer, que ensinam enquanto mostram, contribuem para a formação dos mais jovens em diversos aspectos, entre eles as questões éticas e ecológicas, que evidenciam como concepções, vivências e aprendizagens se entrelaçam na relação que essas comunidades rurais tradicionais mantêm com a natureza.

\section{Referências}

AFONSO, Leônidas Marques. História de Jaboticatubas. Jaboticatubas: [s.n.], 1957.

ALMEIDA, Alfredo Wagner Berno de. Terras tradicionalmente ocupadas: processos de territorialização e movimentos sociais. Revista Brasileira de Estudos Urbanos e Regionais. V.6, n.1, 2004.

ARRUDA, Rinaldo. Populações Tradicionais e a proteção dos recursos naturais em Unidades De Conservação. Ambiente \& Sociedade, Ano II, n.5, p.79-92, $2^{\circ}$ Semestre de 1999. Disponível em: <http://www.scielo.br/pdf/asoc/n5/n5a07> Acesso em 04 mai. 2017.

CARNEIRO DA CUNHA, Manuela.; ALMEIDA, Mauro W. Barbosa de. Populações tradicionais e conservação ambiental. In: CUNHA, M. C. Cultura com aspas: e outros ensaios. São Paulo: Cosac Naify, 2009. p. 277-300.

CARVALHO, Isabel Cristina de Moura. Qual educação Ambiental: elementos para um debate sobre educação ambiental popular e extensão rural. Revista Agroecologia e Desenvolvimento Rural Sustentável, v.2, n.2, p. 43-51, 2001.

CARVALHO, Karina Jácome. et al. Ecologia, manejo, silvicultura e tecnologia da macaúba. Convênio de Cooperação Técnica SECTES/FAPEMIG. Universidade Federal de Viçosa. Viçosa, 2011. Disponível em: $<$ http://www.ciflorestas.com.br/arquivos/d b b 15592.pdf $>$ acesso em 04 mar. 2018.

DIEGUES, Antônio Carlos Santana. O mito moderno da natureza intocada. 3. ed. São Paulo: Hucitec Núcleo de Apoio à Pesquisa sobre Populações Humanas e Áreas Úmidas Brasileiras, USP, 2001. 
FERREIRA, Luiz Felipe. Acepções recentes do conceito de lugar e sua importância para o mundo contemporâneo. Revista Território, n.09, p. 65-83, 2000. Disponível em:<http://www.laget.eco.br/territorio/sumario 09.htm> Acesso em 05 jan. 2018

GONÇALVES, José Reginaldo dos Santos. O patrimônio como categoria de pensamento. In: ABREU, R.; CHAGAS, M. (Orgs) Memória e patrimônio ensaios contemporâneos. Rio de Janeiro: Lamparina, 2009. p. 25-33.

HALBWACHS, Maurice. A memória coletiva. Tradução Laurent Léon Shaffter . São Paulo: Editora Revista dos Tribunais, 1990.

HARTMANN, Luciana. Tomazito, eu e as narrativas: "Porque estoy hablando de mi vida”.In: GONÇALVES, M. A.; MARQUES, R.; CARDOSO, V. Z. Etnobiografia: subjetivação e etnografia. Rio de Janeiro: 7 Letras, 2012. p.179- 206.

INGOLD, Tim. Da transmissão de representações à educação da atenção. Educação, v. 33, n. 1, p. 6-25, 2010. Disponível em:

〈http://revistaseletronicas.pucrs.br/ojs/index.php/faced/article/viewFile/6777/4943Aces $>$ Acesso em 20 dez. 2017.

Chega de Etnografia! Educação, v.39, n.3.p.404-411, set-dez, 2016.

LEFF, Enrique. Epistemologia Ambiental. São Paulo: Cortez, 2003.

LOPES FILHO, José Divino ; MAGALHÃES, Cristiane Maria. A Manufatura Têxtil Cana do Reino: patrimônio industrial e memória histórica em Santana do Riacho, MG. In: SEMINÁRIO ACIONAL DE HISTÓRIA DA CIÊNCIA E DA TECNOLOGIA, n.14, 2014. Belo Horizonte. Anais. Belo Horizonte: SNHCT, 2014. Disponível em: $\langle$ http://www.14snhct.sbhc.org.br/conteudo/view?ID_CONTEUDO=800 $>$ Acesso em 20 jun. 2017. http://www.14snhct.sbhc.org.br/conteudo/view?ID_CONTEUDO=800> Acesso em 20 jun. 2017.

LIMA, Júnia de Souza. De meninas fiandeiras a mulheres operárias: a inserção da mão-de-obra feminina na Companhia de Fiação e Tecidos Cedro e Cachoeira (1872 1930). 2009. 201f. Dissertação (Mestrado em Educação Tecnológica) - Centro Federal de Educação Tecnológica de Minas Gerais - CEFET-MG, Belo Horizonte.

MARQUES, José Geraldo. Pescando pescadores: ciência e etnociência em uma perspectiva ecológica. 2. ed., São Paulo: NUPAUB/USP,2001.

MEDEIROS, Patrícia. et al. Uso de estímulos visuais na pesquisa Etonbiológica. In: ALBUQUERQUE et al. Métodos e técnicas na pesquisa Etnobiológica e Etnoecologica. Recife: NUPPEA, 2010. p.153-169.

MINAYO, Maria Cecília de Souza. O desafio do Conhecimento: Pesquisa qualitativa em saúde.7.ed.São Paulo: Hucitec ,2000.

PORTELLI, Alessandro. A história oral como arte da escuta. São Paulo: Letra e Voz, 2016. 
RIBEIRO, Ricardo Ferreira. Cerrado, o coração do Brasil. In: DIAS, J.; LAUREANO, L (Coord.) Farmacopéia popular do Cerrado. Goiás: Articulação Pacari, 2009. P.26-31.

ROCHA, Eloísa Acires Candal. Porque ouvir as crianças? Algumas questões para um debate científico multidisciplinar. In. CRUZ, S. H. V. (Org.). A criança fala: a escuta de crianças em pesquisas. São Paulo: Cortez, 2008

SERRES, Michel. O Contrato Natural. 2.ed. Lisboa: Instituo Piaget, 1990.

SILVA, Peterson Rigato da. Teoria e prática na pesquisa com crianças: diálogos com William Corsaro. Pro-Posições, Campinas, v. 23, n. 2, p. 223-228, 2012. Disponível em: $<$ http://www.scielo.br/scielo.php?script=sci_arttext\&pid=S0103-

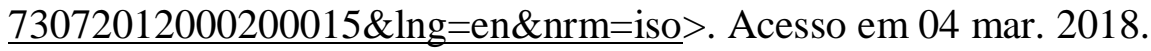

TOLEDO, Vitor. M.; BARRERA-BASSOLS, Narciso. A memória biocultural: a importância ecológica das sabedorias tradicionais. Tradução Rosa L. Peralta. São Paulo: Expressão Popular, 2015.

TUAN, Yi-Fu. Topofilia: um estudo da percepção, atitudes e valores do meio ambiente. Tradução Lívia de Oliveira. Londrina: Eduel, 2012

VIVEIROS DE CASTRO, Eduardo. O recado da Mata. Prefácio in: KOPENAWA, D.; ALBERT, B. A queda do céu : Palavras de um Xamã Yanomami. São Paulo: Companhia das Letras, 2015.

WANDERLEY, Maria Nazaré Baudel. Agricultura familiar e campesinato: rupturas e continuidades. Estudos sociedade e agricultura, Rio de janeiro, p. 42-61. Outubro de 2003. Disponível em: <https://wp.ufpel.edu.br/leaa/files/2014/06/Texto-6.pdf $>$ acesso 20 jan. 2018.

Submetido em: 22-04-2019.

Publicado em:20-047-2019. 